\title{
Briefing: A systemic framework for infrastructure need assessment
}

Tom Dolan BSC, MSc, MBA, EngD

Senior Research Associate, UKCRIC Co-ordination Node (ESPRC Grant Ref.

EP/R017727/1), Department of Civil, Environmental and Geomatic

Engineering, University College London, London, UK

(thomas.dolan@ucl.ac.uk) (Orcid:0000-0002-3192-3073)

In the absence of a clearly articulated, shared, collaboratively developed and mutually understood strategic vision of the desired outcomes that infrastructure is expected to enable (purpose), it is not possible to fully evaluate system performance gaps or assess infrastructure need. This is significant for any country, region, city, town or community aiming to cost-effectively improve the performance and resilience of its infrastructure systems. A systemic, collaborative, transparent, structured and flexible framework for infrastructure need assessment and decisionmaking is proposed. The proposed framework is systemic; is built on a set of strategic need assessment principles; explicitly aligns need assessment with the desired outcomes that infrastructure systems are expected to enable; prioritises underlying systemic priorities such as resilience; assesses infrastructure system performance and diagnoses infrastructure need from four perspectives; requires outcomes and needs to be neutrally framed; and prescribes transparent evaluation of options against clearly defined systemic and outcome-aligned selection criteria.

\section{Introduction}

Achieving long-term value-for-money from infrastructure systems is a question of doing the systemically right thing right, not the wrong thing better (Beckford, 2013). The process of infrastructure need assessment has a significant role to play in enabling this by (a) developing a systemic vision and clearly stating systemic priorities to underpin the identification of systemically right things, and (b) identifying systemic performance gaps (wrong things) to diagnose infrastructure need.

However, the credibility of recommendations made by any infrastructure need assessment is dependent on the quality, transparency and inclusivity of the methodological approach used to perform the assessment. Therefore, infrastructure need assessment must be aligned with and driven by a clearly defined set of strategic need assessment principles and be underpinned by a transparent, systemic, structured, interconnected and flexible methodological framework. It must also generate a coherent narrative and audit trail to both record and justify all decisions made during, and all recommendations arising from, the need assessment process.

This methodological need is significant to any country, region, city, town or community grappling with the challenge of improving systemic infrastructure decision-making processes. Furthermore, the development of an infrastructure need assessment process aligned with the desired societal outcomes that infrastructure systems are expected to enable has the potential to identify fit-for-purpose solutions, which are less likely to experience delays in the planning phase and are more likely to deliver stable returns over the investment life cycle. Therefore, such a process is of potential value to all involved with infrastructure system provision, funding, financing and operation.
Moreover, in the UK, where a pipeline of future sector-specific infrastructure projects is regularly published (HM Treasury and IPA, 2016a, 2016b), the National Infrastructure Commission (NIC) has a mandate to undertake a National Infrastructure Assessment (NIA) once per parliament (HM Treasury, 2017; NIC, 2017). 'Better' infrastructure has been prioritised to support the delivery of industrial strategy objectives (HM Government, 2017), and Her Majesty's Treasury (HM Treasury) have commissioned a special study into the resilience of economic infrastructure systems (NIC, 2018); this methodological need is particularly relevant.

The research presented in this paper develops a systemic, collaborative, transparent, structured and flexible framework for infrastructure need assessment and decision-making in response to this methodological need (Figure 1). This framework (Figure 1) is based on the identification of a set of strategic need assessment principles (orange boxes in Figure 1) and a nine-stage infrastructure need assessment and decision-making framework aligned with these principles (see blue boxes in Figure 1).

The sections that follow provide an overview of the context in which this research was developed and provide an overview of each framework stage (Figure 1), strategic need assessment principles (Figure 1) and the steps required to put the framework into practise (Tables 1-9). The paper concludes by providing a summary of the unique features of the proposed framework.

\section{Supporting context}

This research builds on earlier research undertaken on behalf of Infrastructure UK to develop a process for outcome-oriented performance indicators (PIs) for infrastructure systems (Carhart et al., 2016; Dolan et al., 2016); research developed in direct response to the launch of the NIC and a consultation regarding 


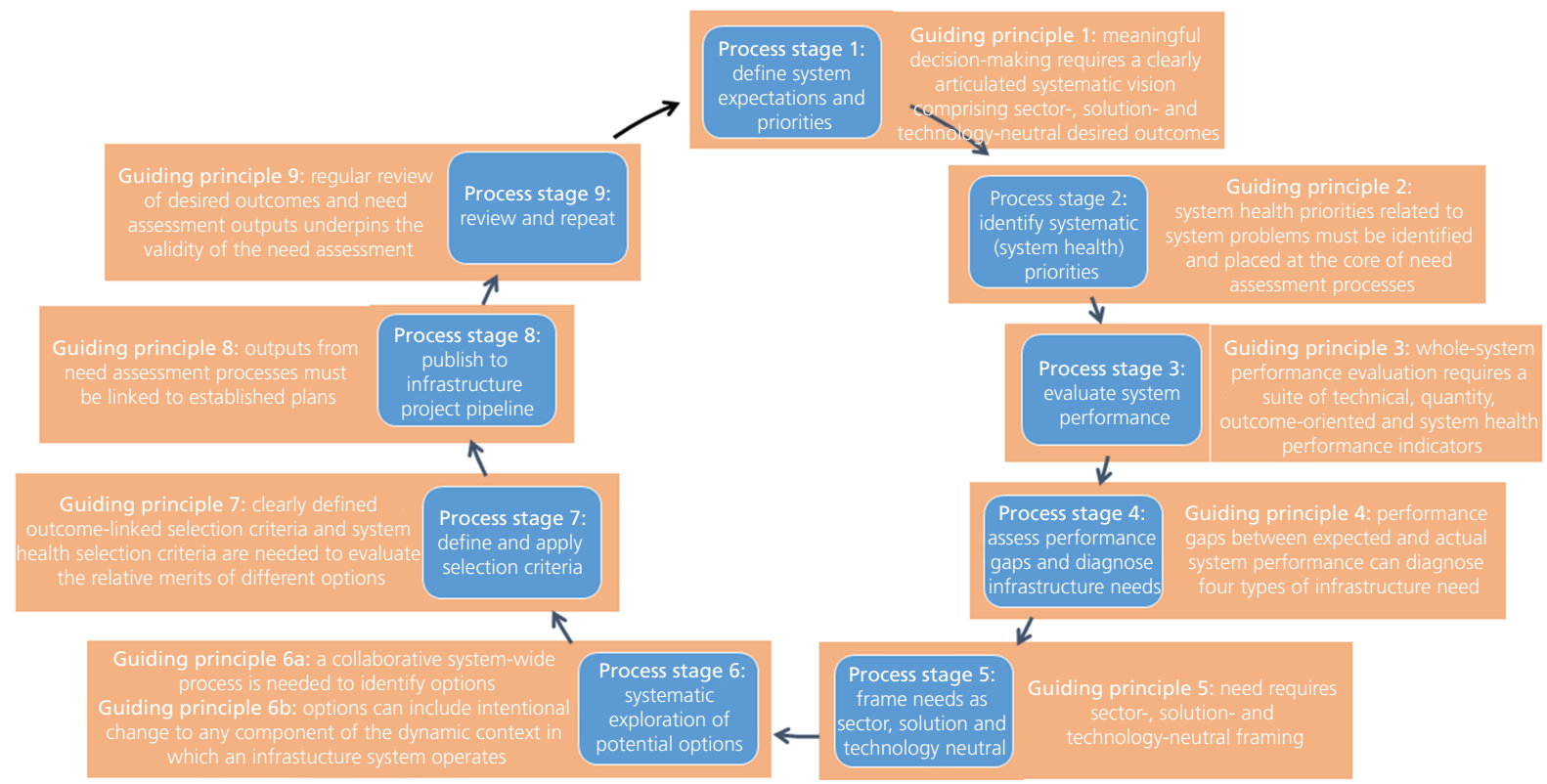

Figure 1. A systemic, collaborative, transparent, structured and flexible framework for infrastructure need assessment and decision-making

NIA methodology (Dolan, 2015, 2016; HM Treasury, 2016); research on analysing infrastructure resilience as a system problem (Dolan and Cosgrave, 2016; Dolan et al., 2018); and research on developing approaches to frame the societal outcomes that infrastructure systems are expected to enable using solution-, sector- and technology-neutral language.

In particular, the need assessment and decision-making framework proposed here and illustrated in Figure 1 is informed by a number of conclusions drawn from the aforementioned body of work, specifically.

The ability to perform a complete and systemic assessment of infrastructure need is significant for any country, region, city, town or community that aims to cost-effectively improve the quality and resilience of its infrastructure systems and make fitfor-purpose infrastructure investments capable of enabling the societal outcomes expected.

In the absence of a clearly articulated, shared, collaboratively developed and mutually understood strategic vision composed of a set of statements of the desired outcomes that infrastructure systems are expected to enable, it is not possible to fully evaluate system performance. Specifically, it is not possible to identify systemic performance gaps where actual performance of the infrastructure system is not sufficiently aligned with the outcomes expected, from which it follows that it is not possible to undertake a complete systemic assessment of underlying infrastructure system need (Dolan and Cosgrave, 2016).

Additionally, in the absence of a strategic vision, there is a tendency to derive assumptions of infrastructure purpose wrongly and frame assessments of future infrastructure need in terms of the technical characteristics of infrastructure assets already in operation. As a consequence, infrastructure need is often defined in sector-, solutionor technology-specific terms rather than in terms of the outcomes that the infrastructure system is expected to enable. Thus, the solutions to infrastructure need are often assumed to be obvious, and the need for collaborative system-wide processes to enable the identification of common needs that span multiple sectors and identify opportunities for innovative solutions are overlooked. Consequently, in the absence of a strategic vision, the range of options considered in response to infrastructure need can be constrained to an unnecessary extent and innovative systemic approaches are inhibited.

Infrastructure is a complex interdependent network of networks. It is, therefore, vulnerable to the emergence of systemic problems for example, challenges associated with resilience, carbon dioxide mitigation, flood management, climate change preparedness and sustainability. These systemic problems emerge as a consequence of interdependent interactions within networks, between networks, and between the networks and the external political, social and economic contexts in which they are embedded. Systemic problems such as these are best managed collaboratively at the system level, using a portfolio of systemically targeted actions. Furthermore, system problems, if not prioritised, can jeopardise the achievement of all other long-term strategic priorities. Therefore, infrastructure need assessment and decision-making must be systemic in scope, if systemic problems are to be managed as effectively as possible (Dolan and Cosgrave, 2016; Dolan and Hiteva, 2017; Dolan et al., 2016).

Infrastructure interdependence analysis (Boin and McConnell, 2007; Carhart and Rosenberg, 2016; Rinaldi et al., 2001; Rosenberg 
et al., 2014) has significant explanatory power and is a substantially broader concept than mere dependence on the immediate inputs that infrastructure systems require to function. Infrastructure systems are also interdependent with the dynamic external context (social, political, economic, financial, legal, environmental, regulatory, local, global, spatial and temporal) in which they operate. Therefore, understanding of interdependencies is needed to better understand and improve system performance. Furthermore, if interdependencies are well understood, an intentional change to any of the aforementioned contextual factors can theoretically be used as a strategy to improve system performance. However, there is a tendency to focus predominantly on engineered solutions and overlook the significance of these other options (Dolan and Hiteva, 2017).

To capitalise fully on the transformative opportunity created by the need for a regular NIA, a systemic collaborative, transparent, structured and flexible framework for infrastructure need assessment and decision-making is needed (Dolan, 2015; Dolan and Cosgrave, 2016; Dolan and Hiteva, 2017).

\section{Systemic need assessment guiding principles and framework}

The infrastructure need assessment and decision-making framework (henceforth the framework) in Figure 1 is based on the identification of a set of strategic need assessment principles (orange boxes in Figure 1) and a nine-stage infrastructure need assessment and decision-making framework aligned with these principles (see blue boxes in Figure 1).

This section is structured using the framework stages as subheadings and provides a brief overview of the how each process stage and strategic need assessment principle contributes to the framework (Figure 1). Additionally, steps for implementing each process stage are proposed and outlined (Tables 1-9).

\subsection{Process stage 1: define system expectations and priorities}

Stage 1 aligns with the following strategic need assessment principle: meaningful decision-making requires a clearly articulated systemic vision comprising sector-, solution- and technology-neutral desired outcomes (statements of expectations).

The development of a shared, collaborative and mutually understood statement of the desired outcomes that an infrastructure system is expected to enable is essential for three main reasons. First, it provides the basis to articulate a systemic vision of infrastructure system purpose. Second, it provides a foundation for all subsequent stages of the proposed need assessment and decision-making framework (Figure 1). Third, it creates an aspirational frame of reference against which all subsequent decisions and evaluations of system performance can be justified.

However, a systemic vision requires certain characteristics if it is to perform this function and support the need assessment framework in Figure 1. It must be $(a)$ an accurate and inclusive representation of expectations; $(b)$ comprise a set of wellstructured, unambiguous, mutually understood and mutually accepted desired outcomes; (c) systemic in scope and sector neutral, not aligned with a specific infrastructure sector; (d) solution neutral, not aligned with any specific solution or mode of delivery; and (e) technology neutral, not aligned with the incumbent or any other technology.

Significantly, consensus is not a necessary component of a systemic vision provided that the systemic vision is mutually understood and accepted. Steps 1.1 to 1.4 in Table 1 are proposed to ensure that the systemic vision developed has these characteristics.

The sector-, solution- and technology-neutral framing of desired outcomes is particularly significant because any bias or anchoring introduced at this stage will similarly bias or anchor decisions made at all subsequent stages of the framework (Figure 1).

\subsection{Stage 2: define systemic (system health) priorities}

Stage 2 aligns with the following strategic need assessment principle: system health priorities related to system problems must be identified and placed at the core of need assessment processes.

Table 1. Overview of proposed steps and actions to implement stage 1

\begin{tabular}{|c|c|c|}
\hline Step & Overview & Potential benefit(s) \\
\hline $\begin{array}{l}1.1 \text { Identify desired outcomes } \\
\text { (expectations) }\end{array}$ & $\begin{array}{l}\text { A process to engage citizens, communities, industry, investors, } \\
\text { government and other interested parties in identification of } \\
\text { the desired outcomes that they expect infrastructure to play a } \\
\text { role in enabling }\end{array}$ & $\begin{array}{l}\text { An accurate and inclusive representation of } \\
\text { expectations of the infrastructure system }\end{array}$ \\
\hline $\begin{array}{l}1.2 \text { Clarify and structure } \\
\text { desired outcomes }\end{array}$ & $\begin{array}{l}\text { A process to enable in-depth discussion, analysis, visualisation } \\
\text { and structured mapping of the desired outcomes identified } \\
\text { through step } 1.1\end{array}$ & $\begin{array}{l}\text { A set of well-structured, unambiguous, } \\
\text { mutually understood and accepted desired } \\
\text { outcomes }\end{array}$ \\
\hline $\begin{array}{l}\text { 1.3 Frame desired outcomes } \\
\text { in neutral terms }\end{array}$ & $\begin{array}{l}\text { A process to remove any sector-, technology- or solution- } \\
\text { specific terminology from the framing of desired outcomes }\end{array}$ & $\begin{array}{l}\text { Systemic, unbiased framing not anchored } \\
\text { towards specific solutions or technologies }\end{array}$ \\
\hline 1.4 Set systemic vision & A process to convert the above into a shared systemic vision & $\begin{array}{l}\text { An aspirational direction of travel against } \\
\text { which all subsequent decisions and } \\
\text { evaluations can be justified }\end{array}$ \\
\hline $\begin{array}{l}\text { 1.5 Define outcome-linked } \\
\text { selection criteria }\end{array}$ & See step 7.1 in Table 7 & See step 7.1 in Table 7 \\
\hline
\end{tabular}


System problems are unplanned emergent properties that emerge as a consequence of interdependent interactions within networks, between networks, and between networks and the external political, social and economic contexts in which they are embedded. Significantly, system problems are not caused by any single infrastructure sector operating in isolation and likewise cannot be resolved in isolation from the wider systemic context. Therefore, the root causes of system problems are most effectively diagnosed collaboratively at the system level, and are best managed collaboratively at the system level using a portfolio of systemically targeted actions that address systemic root causes rather than sectoral symptoms (Dolan and Cosgrave, 2016; Dolan and Hiteva, 2017; Dolan et al., 2016).

Furthermore, system problems, if not prioritised, can jeopardise the achievement of all other long-term strategic priorities. Therefore, infrastructure need assessment and decision-making must be systemic in scope, if systemic problems are to be managed as effectively as possible. System problems become systemic (system health) priorities when the system as currently configured and/or operated is vulnerable to a systemic problem which, if not addressed, has the potential to jeopardise the achievement of all other long-term priorities.

Therefore, any methodology for the assessment of infrastructure need must include processes to identify systemic problems, improve understanding of these and diagnose whether a system problem should be managed as a systemic priority. Furthermore, it is necessary to evaluate the impact of any recommended change to the infrastructure system on systemic priorities. Table 2 proposes four steps to put stage 2 into practise.

\subsection{Stage 3: evaluate system performance}

Stage 3 aligns with the following strategic need assessment principle: whole-system performance evaluation requires a suite of PIs covering technical PI, quantity PI, outcome-oriented PI and system health PI.

To fully understand system performance, it is necessary to evaluate performance from a range of different perspectives using a suite of technical, quantity, outcome-oriented, system health PIs (Dolan et al., 2016). As a suite of PIs, these four PI types provide complementary insights and enable a meaningful assessment of whole-system performance.

Indicators of technical performance (technical PIs) have the purpose of measuring and providing insight into real-time performance and are typically used at the tactical or operational level by infrastructure operators to inform real-time and short-term operating decisions and ensure that an asset, component or process operates as efficiently (and effectively) as possible. Technical PIs for a system component are typically fixed in line with technical specifications (typically those expected and/or designed for when the system component was commissioned) and typically remain constant over the life cycle of an infrastructure asset or system component.

Indicators of quantity of provision (quantity PIs) focus mainly on measuring either inputs or outputs. Quantity PIs enable evaluation of whether current provision (supply) is sufficient to meet demand. Additionally, quantity PIs can be combined with projections of future demand to assess whether the current infrastructure capacity will be sufficient to meet future demand.

Outcome-oriented PIs are a form of strategic PIs directly aligned with one or more 'desired outcomes' that infrastructure is expected to enable (Carhart et al., 2016; Dolan et al., 2016).

Indicators of systemic priorities (system health PIs) are a form of outcome-oriented PIs aligned not with desired outcomes but with system health priorities.

Table 3 proposes four steps to put stage 3 into practise.

\subsection{Stage 4: assess performance gaps and diagnose infrastructure needs}

Stage 4 aligns with the following strategic need assessment principle: performance gaps between expected and actual system performance can diagnose four types of infrastructure needs (maintenance/renewal, quantity of provision, alignment and system health).

An infrastructure system is 'fit for purpose' if it enables all of the desired outcomes expected of it and operates without performance gaps. An infrastructure system need exists in any situation where there is a performance gap between actual and expected system

Table 2. Overview of proposed steps and actions to implement stage 2

\begin{tabular}{|c|c|c|}
\hline Step & Overview & Potential benefit(s) \\
\hline 2.1 Identify system problems & A process to identify current system problems & Greater awareness of system problems \\
\hline $\begin{array}{l}2.2 \text { Analyse interdependent origins } \\
\text { of system problems }\end{array}$ & $\begin{array}{l}\text { A process to analyse system interdependencies with a view } \\
\text { to understanding the origin of system problems }\end{array}$ & $\begin{array}{l}\text { In-depth understanding of root causes of, } \\
\text { and systemic resilience to, system } \\
\text { problems }\end{array}$ \\
\hline $\begin{array}{l}2.3 \text { State systemic (system health) } \\
\text { priorities }\end{array}$ & $\begin{array}{l}\text { Based on the above, state systemic (system health) priorities } \\
\text { that must be addressed or alleviated as part of need } \\
\text { assessment }\end{array}$ & $\begin{array}{l}\text { A clearly framed set of priorities for } \\
\text { infrastructure decision-making }\end{array}$ \\
\hline $\begin{array}{l}\text { 2.4 Define system health priority- } \\
\text { linked selection criteria }\end{array}$ & See step 7.2 in Table 7 & See step 7.2 in Table 7 \\
\hline
\end{tabular}


Table 3. Overview of proposed steps and actions to implement stage 3

\begin{tabular}{|c|c|c|}
\hline Step & Overview & Potential benefit(s) \\
\hline $\begin{array}{l}\text { 3.1 Select indicators of technical } \\
\text { performance (technical PIs) }\end{array}$ & $\begin{array}{l}\text { Collaborate with infrastructure operators to identify } \\
\text { available technical Pls already in use, which can be } \\
\text { employed for need assessment purposes and which } \\
\text { elements of technical performance require additional } \\
\text { indicators }\end{array}$ & $\begin{array}{l}\text { A suite of PIs to inform analysis of actual } \\
\text { system performance related to technical, } \\
\text { quantity, alignment and system health; a } \\
\text { foundation for the performance gap } \\
\text { analysis proposed in stage } 4\end{array}$ \\
\hline $\begin{array}{l}3.2 \text { Select indicators of quantity of } \\
\text { provision (quantity PIs) }\end{array}$ & $\begin{array}{l}\text { Develop a set of quantity Pls for national infrastructure to } \\
\text { enable evaluation of whether the current provision } \\
\text { (supply) is sufficient to meet demand }\end{array}$ & \\
\hline $\begin{array}{l}\text { 3.3 Develop outcome-oriented Pls } \\
\text { (alignment PIs) }\end{array}$ & $\begin{array}{l}\text { Apply the outcome-oriented PI process proposed by Carhart } \\
\text { et al. (2016) and Dolan et al. (2016) to develop a set of PIs } \\
\text { identified in part } 1\end{array}$ & \\
\hline $\begin{array}{l}\text { 3.4 Develop indicators of system } \\
\text { health (system health PIs) }\end{array}$ & $\begin{array}{l}\text { Refine the process used in step } 2.3 \text { to create outcome- } \\
\text { oriented Pls for the systemic (system health) priorities } \\
\text { identified in part } 1\end{array}$ & \\
\hline
\end{tabular}

performance. Infrastructure need can be diagnosed through analysis of performance gaps using the four PI types introduced in stage 3. A complete assessment of infrastructure need must include evaluation of four different types of infrastructure need.

- Renewal or maintenance need - this need type can be diagnosed by identifying technical performance gaps. This need type arises where one or more components of an infrastructure asset or system are no longer performing in line with the initial technical specification of the component.

- Quantity of provision need - this need type can be diagnosed by identifying quantity performance gaps. This need type arises where the demand (expectation) for an output or service supplied by the infrastructure system is greater than the supply capacity of the system (actual) for that output or service. Quantity need can take two forms: $(a)$ current, where current demand is greater than supply, or $(b)$ predicted future, where future demand is predicted to exceed supply capacity in the future.

- Outcome-oriented or alignment need - this need type can be diagnosed by identifying alignment performance gaps. This need type emerges where actual system performance is no longer aligned with the desired outcomes expected by society. In these cases, expected outcomes are not $100 \%$ satisfied because the infrastructure is not capable of enabling the desired outcomes as currently expressed.

- System health need - this need type can be diagnosed by identifying system health performance gaps. This need type emerges when the system as currently configured and/or operated is vulnerable to an emergent system problem, which if not addressed has the potential to jeopardise the achievement of all other long-term priorities.

Table 4 proposes four steps to put stage 4 into practise.

Table 4. Overview of proposed steps and actions to implement stage 4

\section{Step}

4.1 Identify technical performance gaps

4.2 Identify current quantity performance gaps

4.3 Identify projected future quantity performance gaps

4.4 Identify outcome-oriented performance gaps

4.5 Identify system health performance gaps

\section{Overview}

A process to identify components of an infrastructure asset or system that are not performing to the technical specifications that they were designed to meet or to the technical specification expected by the operator (technical performance gaps)

A process to identify any situation where the demand (expectation) for an output or service supplied by the infrastructure system is currently greater than the supply capacity of the system (actual) for that output or service

As above, but based on scenarios linked to drivers of changing demand, drivers of changes to current supply capacity, to identify under what plausible future scenarios the demand (expectation) for an output or service supplied by the infrastructure system is projected to be greater than the supply capacity of the system (actual) for that output or service

A process to identify any situation where actual system performance is no longer aligned with the desired outcomes expected by society (outcome-oriented performance gaps)

A three-part process to

(a) identify where the system as currently configured and/or operated system is vulnerable to system problems

(b) assess whether system problems identified in the previous assessment have changed in status

(c) assess whether system problems or vulnerabilities will emerge as a consequence of planned changes to current patterns of system use, or change to external context (i.e. what system needs must be addressed if system failure is not to jeopardise the long-term realisation of the outcomes that are expected) 
Table 5. Overview of proposed steps and actions to implement stage 5

\begin{tabular}{|c|c|c|}
\hline Step & Overview & Potential benefit(s) \\
\hline $\begin{array}{l}\text { 5.1 Frame performance gaps } \\
\text { identified as option-, sector- and } \\
\text { technology-neutral needs }\end{array}$ & $\begin{array}{l}\text { A process to collate performance gaps and ensure that } \\
\text { framing is in sector-, solution- and technology-neutral } \\
\text { terms and reframe need wherever necessary }\end{array}$ & $\begin{array}{l}\text { Framing need in neutral terms enables (a) the } \\
\text { identification of common needs that span } \\
\text { multiple sectors and }(b) \text { the opportunity for } \\
\text { innovative solutions to be considered }\end{array}$ \\
\hline 5.2 Root cause analysis & $\begin{array}{l}\text { A process to analyse and diagnose the root causes of the } \\
\text { performance gaps identified and to analyse whether } \\
\text { performance gaps can be clustered as 'symptoms' of a } \\
\text { shared systemic common cause }\end{array}$ & $\begin{array}{l}\text { Develop deeper understanding of the } \\
\text { systemic causes of performance gaps }\end{array}$ \\
\hline
\end{tabular}

\subsection{Stage 5: frame infrastructure need as sector, solution and technology neutral}

Stage 5 aligns with the following strategic need assessment principle: need requires sector-, solution- and technology-neutral framing.

At stage 1, it was stated that a systemic vision requires certain characteristics if it is to support the infrastructure need assessment framework in Figure 1. Similarly, any statement of infrastructure need diagnosed through application of Figure 1 must be $(a)$ sector neutral, not aligned with a specific infrastructure sector; (b) solution neutral, not aligned with any specific solution or mode of delivery and $(c)$ technology neutral, not aligned with the incumbent or any other technology. Neutral framing of the strategic vision at stage 1 aims to avoid bias or anchoring being introduced into the need assessment. Stage 5 is intended to provide quality control to ensure that this is the case for statements of infrastructure need diagnosed through application of Figure 1 . Table 5 proposes two steps to put stage 5 into practise.

\subsection{Stage 6: systemic exploration of potential options} Stage 6 aligns with the following strategic need assessment principles: a collaborative system-wide process is needed to identify options to address need (conversion of need into solution is non-trivial) and options can include any intentional change to any component of the dynamic context in which an infrastructure system operates.

In an interdependent context, any intentional change to any of the contextual factors that characterise the broader external context within which an infrastructure system is embedded (i.e. social, political, economic, regulatory, financial, legal, environmental, local, global, spatial and temporal) can be used as a strategy to address an infrastructure need (Dolan and Hiteva, 2017). However, conventional approaches often focus primarily on implementing tried-and-tested sector-level technical fixes (typically engineered solutions) in response to performance gaps observed at the sector level, with little reference to the possible systemic root causes of the performance gap observed.

It follows that little, if any, attention is given to $(a)$ understanding the performance gap as a symptom of a broader system-wide problem, $(b)$ the identification of common needs that span multiple sectors or $(c)$ the opportunity for innovative solutions to be sourced from outside of sector. Therefore, it is important to break the implicit connection between need and solution assumed in many conventional approaches to infrastructure decisionmaking and acknowledge that the potential option space is significantly broader than that traditionally considered. Options to address a need can be based on a portfolio of responses; targeted actions in other infrastructure sectors; targeted change to any interdependent element of the broader system; adopting bestpractice approaches from elsewhere in the infrastructure system or from outside the infrastructure system; innovative business models that deliver services in non-traditional ways; and innovative solutions enabled by digital technologies or problem avoidance based on understanding the root cause of the observed problem. Stage 6 complements step 1.3 of stage 1 (Table 1) and step 5.1 of stage 5 (Table 5) on the neutral framing of desired

Table 6. Overview of proposed steps and actions to implement stage 6

\begin{tabular}{|c|c|c|}
\hline Step & Overview & Potential benefit(s) \\
\hline $\begin{array}{l}\text { 6.1 Publish list of neutrally framed } \\
\text { infrastructure needs (infrastructure } \\
\text { need pipeline) }\end{array}$ & $\begin{array}{l}\text { Regularly publishing the neutrally framed statements of } \\
\text { infrastructure needs identified at stage } 5 \text { (Table } 5 \text {, step 5.1) } \\
\text { Promote these statements to create transparency and signal } \\
\text { clearly the infrastructure needs where action is required }\end{array}$ & \\
\hline 6.2 Invite option proposals & $\begin{array}{l}\text { Invite the proposal of options aligned to the infrastructure } \\
\text { needs published in step } 6.1 \\
\text { Make the process accessible to non-traditional actors and invite } \\
\text { cross-sectoral solutions }\end{array}$ & $\begin{array}{l}\text { Broadens the option space; creates a } \\
\text { marketplace to engage with possible } \\
\text { solution providers, greatly increasing } \\
\text { the potential for innovative options }\end{array}$ \\
\hline $\begin{array}{l}\text { 6.3 Cross-sectoral and public } \\
\text { engagement }\end{array}$ & $\begin{array}{l}\text { Develop a suite of processes to drive engagement around the } \\
\text { list of infrastructure need pipeline (step 6.1) and support the } \\
\text { submission of option proposals }\end{array}$ & to be identified \\
\hline
\end{tabular}


outcomes and infrastructure needs by explicitly focusing on processes to broaden the option space considered in response to statements of infrastructure need. Table 6 proposes two steps to put stage 6 into practise.

\subsection{Stage 7: define and apply selection criteria}

Stage 7 aligns with the following strategic need assessment principle: clearly defined outcome-linked selection criteria and system health selection criteria are needed to evaluate the relative merits of different options.

Successful implementation of stage 6 will increase the number and diversity of options proposed in response to any infrastructure need. A transparent set of methodologies to consistently evaluate the relative merits of different options against the desired outcomes and systemic priorities identified in stages 1 and 2 is required. It is proposed that to do this outcome-linked selection, criteria are developed from the desired outcomes identified in the systemic vision (Table 1, steps 1.4 and 1.5) and systemic prioritylinked selection criteria are developed from the system health priorities identified at stage 2 (Table 2, step 2.3). Table 7 gives an overview of what is needed.

\subsection{Stage 8: publish to infrastructure project pipeline}

Stage 8 aligns with the following strategic need assessment principle: need assessment outputs must be clearly linked to established plans. Table 8 gives an overview of what is needed.

\subsection{Stage 9: regular review}

Stage 9 aligns with the following strategic need assessment principle: regular review of desired outcomes, and need assessment outputs, underpins the validity of the need assessment.

\section{Conclusions and recommendations}

This paper summarises the methodological need for and develops a systemic, collaborative, transparent, structured and flexible framework for infrastructure need assessment and decisionmaking (Figure 1). The framework integrates a set of strategic need assessment principles into a nine-stage infrastructure need assessment process (Figure 1). Steps to put each stage into practise are proposed in Tables 1-9.

This framework (Figure 1) includes a number of features absent in other need assessment processes, specifically the following.

Table 7. Overview of proposed steps and actions to implement stage 7

\begin{tabular}{|c|c|c|}
\hline Step & Overview & Potential benefit(s) \\
\hline $\begin{array}{l}\text { 7.1. Define outcome-linked } \\
\text { selection criteria }\end{array}$ & $\begin{array}{l}\text { A process to convert the desired outcomes identified in step } \\
1.3 \text { (Table 1) into a set of sector-, solution-, technology- } \\
\text { neutral outcome-linked selection criteria suitable for use } \\
\text { as (a) guidance for those proposing options in stage } 6 \text { and } \\
\text { (b) for evaluation of options identified in stage } 6\end{array}$ & \multirow{4}{*}{$\begin{array}{l}\text { Establishing a clear link between the systemic } \\
\text { vision, system priorities and decision-making } \\
\text { processes in this way enables transparent } \\
\text { defensible decision-making to enable } \\
\text { expectations and manage systemic priorities. } \\
\text { It also provides need assessment } \\
\text { recommendations with credibility }\end{array}$} \\
\hline $\begin{array}{l}\text { 7.2 Define system health } \\
\text { priority-linked selection } \\
\text { criteria }\end{array}$ & $\begin{array}{l}\text { A process to convert the systemic (system health) priorities } \\
\text { identified in stage } 2 \text { (Table } 2 \text {, step } 2.3 \text { ) into a set of } \\
\text { systemic priority-linked selection criteria }\end{array}$ & \\
\hline 7.3 Publish selection criteria & $\begin{array}{l}\text { Publish the decision criteria identified in steps } 7.1 \text { and } 7.2 \\
\text { alongside the infrastructure need pipeline in step } 6.1\end{array}$ & \\
\hline 7.3 Apply selection criteria & $\begin{array}{l}\text { A process to apply the selection criteria identified in steps } \\
7.1 \text { and } 7.2 \text { to evaluate which of the options identified in } \\
\text { stage } 6 \text { are most fit for purpose }\end{array}$ & \\
\hline
\end{tabular}

Table 8. Overview of proposed steps and actions to implement stage 8

$\begin{array}{lcc}\text { Step } & \text { Overview } & \text { Potential benefit(s) } \\ \text { 8.1 Publish the decisions made } & \text { A process to link need assessment decisions to the established } & \text { Create certainty for investors and other } \\ \text { in step } 7.3 \text { (Table 7) } & \text { portfolio of planned actions and delivery plans } & \text { infrastructure practitioners }\end{array}$

Table 9. Overview of proposed steps and actions to implement stage 9

$\begin{array}{lcc}\text { Step } & \text { Overview } & \text { Potential benefit(s) } \\ \begin{array}{l}\text { 9.1 Repeat stages 1-8 } \\ \text { every } 5 \text { years }\end{array} & \text { Follow stages } 1-8 \text { of this process for every subsequent NIA. } & \text { Regular review ensures the credibility of } \\ \begin{array}{l}\text { 9.2 Review needs pipeline } \\ \text { every } 5 \text { years }\end{array} & \text { A process to review whether a need put into the pipeline in } & \text { recommendations from the need assessment } \\ \begin{array}{c}\text { 9.3 Review projects in } \\ \text { pipeline every } 10 \text { years }\end{array} & \text { A prop } 4.1 \text { at the previous NIA remains fit for purpose } & \text { pipeline projects is needed to ensure that need } \\ \text { pipeline over } 10 \text { years ago remains fit for purpose } & \text { and projects remain fit for purpose in the period }\end{array}$


- To make the rationale underpinning each stage transparent and defensible, the framework is built on a set of strategic need assessment principles.

- The framework explicitly aligns infrastructure need assessment with the desired outcomes that infrastructure systems are expected to enable.

- The framework explicitly incorporates underlying systemic priorities such as resilience which, if not addressed, can adversely affect system performance.

- The framework prescribes evaluation of infrastructure system performance from four complementary perspectives and the diagnosis of four different types of infrastructure need.

- All stages of the framework are sector neutral. This supports a systemic need assessment capable of identifying needs that are common across multiple sectors, diagnosing the root causes of these needs and selecting the systemically mosteffective options to treat underlying need at the system level rather than targeting need symptoms at the sector level.

- All stages of the framework are solution and technology neutral. The aim is to enable infrastructure need to be stated in terms independent of any specific solution or technology, thus supporting identification of potential options from a much broader option space than that traditionally considered.

- The need assessment framework requires explicit definition of outcome-linked and system priority-linked selection criteria as part of an objective process to evaluate the relative merits of possible options against transparent selection criteria.

It is recommended that the framework (Figure 1) be used for one of three purposes: $(a)$ to conduct an infrastructure need assessment, (b) to inform the design of infrastructure need assessment methodology or (c) to support critical evaluation, review and refinement of established need assessment methodologies.

\section{Acknowledgements}

This paper is adapted from a conference paper (Dolan, 2017) originally written for the International Symposium for Next Generation Infrastructure 2017 to address the conference theme 'Thinking outside the silo: system-wide purpose, vision and strategy aligning decisions, performance and need assessment with system-wide vision of aspirational outcomes'.

This paper draws on research undertaken as part of $(a)$ the International Centre for Infrastructure Futures (ICIF) (EP/ K012347/1), funded by the Engineering and Physical Sciences Research Council and Economic and Social Research Council, and $(b)$ the UK Collaboratorium for Research into Infrastructure and Cities Co-ordination Node (EP/R017727/1).

The strategic need assessment principles are synthesised from earlier research undertaken on outcome-oriented PIs for Infrastructure UK and the Infrastructure and Projects Authority. This research was developed in direct response to the launch of the NIC and a consultation on need assessment methodology. It draws on ICIF responses to NIC consultations, a policy brief written to the NIC (Dolan and Hiteva, 2017), a policy brief produced for Ciria (Dolan, 2016) and opinion pieces written for Infrastructure Intelligence (Dolan, 2015) and the Institute of Civil Engineers (Dolan and Cosgrave, 2016).

\section{REFERENCES}

Beckford J (2013) Systems Engineering: Necessary but Not Sufficient for 21st Century Infrastructure. Beckford Consulting, Thatcham, UK. Boin A and McConnell A (2007) Preparing for critical infrastructure breakdowns: the limits of crisis management and the need for resilience. Journal of Contingencies and Crisis Management 15(1): 50-59, https://doi.org/10.1111/j.1468-5973.2007.00504.x.

Carhart N and Rosenberg G (2016) Towards a common language of infrastructure interdependency. International Journal of Complexity in Applied Science and Technology 1(1): 35-60, https://doi.org/10.1504/ IJCAST.2016.10002359.

Carhart NJ, Bouch C, Walsh CL and Dolan T (2016) Applying a new concept for strategic performance indicators. Infrastructure Asset Management 3(4): 143-153, https://doi.org/10.1680/jinam.16. 00016.

Dolan T (2015) Infrastructure commission: what are the opportunities and how should it work? Infrastructure Intelligence. See http://www. infrastructure-intelligence.com/article/oct-2015/infrastructurecommission-what-are-opportunities-and-how-should-it-work (accessed 01/12/2018).

Dolan T (2016) The National Infrastructure Commission: Opportunities and Principles to Improve UK Infrastructure (Ciria Briefing Note No. Ref: 04-05-16). Ciria, London, UK.

Dolan T (2017) A systemic, purposeful, performance-led and outcome oriented approach to infrastructure need assessment. Proceedings of ISNGI 2017, London, UK. See http://isngi.org/wpcontent/uploads/2017/10/Tom-Dolan-ISNGI-Session-5.pdf (accessed 13/12/2017)

Dolan T, Carhart N, Jude S, Varga L and Quinn A (2018) Infrastructure Resilience: A Multi-Disciplinary Perspective. International Centre for Infrastructure Futures, University College London, London, UK.

Dolan T and Cosgrave E (2016) Aligning systemic infrastructure decisions with social outcomes. Proceedings of the Institution of Civil Engineers - Civil Engineering 169(4): 147-147, https://doi.org/10. 1680/jcien.2016.169.4.147.

Dolan T and Hiteva R (2017) Policy Brief: the National Infrastructure Assessment - a Transformative Opportunity for UK Infrastructure. Science Policy Research Unit, University of Sussex, Brighton, UK.

Dolan T, Walsh CL, Bouch C and Carhart NJ (2016) A conceptual approach to strategic performance indicators. Infrastructure Asset Management 3(4): 132-142, https://doi.org/10.1680/jinam.16.00015.

HM Government (Her Majesty's Government) (2017) Industrial Strategy: Building a Britain Fit for the Future. HM Government, London, UK.

HM Treasury (Her Majesty's Treasury) (2016) National Infrastructure Commission: Consultation. HM Treasury, London, UK.

HM Treasury (2017) National Infrastructure Commission Framework Document. HM Treasury, London, UK.

HM Treasury and IPA (Infrastructure and Projects Authority) (2016a) National Infrastructure Pipeline 2016. HM Treasury and IPA, London, UK. See https://www.gov.uk/government/publications/nationalinfrastructure-pipeline-2016 (accessed 26/08/2016).

HM Treasury and IPA (2016b) National Infrastructure Delivery Plan 2016 to 2021. HM Treasury and IPA, London, UK, PU 1901.

NIC (National Infrastructure Commission) (2017) Congestion, Capacity, Carbon: Priorities for National Infrastructure - Consultation on National Infrastructure Assessment. NIC, London, UK. 
Smart Infrastructure and Construction Volume 171 Issue SC2
Briefing: A systemic framework for

infrastructure need assessment

Dolan
See https://www.nic.org.uk/wp-content/uploads/Congestion-CapacityCarbon_-Priorities-for-national-infrastructure.pdf (accessed 01/12/2018). NIC (2018) New Resilience Study to Examine How Infrastructure Can Withstand Future Challenges. NIC, London, UK. See https://www.nic. org.uk/news/new-resilience-study-to-examine-how-infrastructure-canwithstand-future-challenges/ (accessed 25/11/2018).
Rinaldi SM, Peerenboom JP and Kelly TK (2001) Identifying, understanding, and analyzing critical infrastructure interdependencies. IEEE Control Systems Magazine 21(6): 11-25, https://doi.org/10.1109/37.969131. Rosenberg G, Carhart N, Edkins AJ and Ward J (2014) Development of a Proposed Interdependency Planning and Management Framework. International Centre for Infrastructure Futures, London, UK.

\section{How can you contribute?}

To discuss this paper, please email up to 500 words to the editor at journals@ice.org.uk. Your contribution will be forwarded to the author(s) for a reply and, if considered appropriate by the editorial board, it will be published as discussion in a future issue of the journal.

Proceedings journals rely entirely on contributions from the civil engineering profession (and allied disciplines). Information about how to submit your paper online is available at www.icevirtuallibrary.com/page/authors, where you will also find detailed author guidelines. 